\title{
The Synthetic Utility of Heteroaromatic Azido Compounds. II. Preparation of Some Furo-, Thieno-, and Selenolo $[3,2-b]$ pyridines
}

\author{
S. GRONOWITZ,* C. WESTERLUND and A.-B. HÖRNFELDT
}

Division of Organic Chemistry 1, Chemical Center, University of Lund, P.O. Box 740, S-220 07 Lund 7, Sweden

A very convenient method for the synthesis of the parent furo-, thieno-, and selenolo[3,2-b]pyridine, and of their 5- and 5,6-substituted derivatives has been found applying the Friedländer reaction to 3-amino-2-formylfuran, -thiophene, and -selenophene. The NMR spectra of these systems have been analyzed, and excellent inverse linear correlations between the electronegativity of the heteroatom and the 7-proton shifts in these systems were found.

The current interest in furo-, thieno-, and selenolopyridines depends largely on two facts. The first is that in these systems a $\pi$-electron excessive nucleus (furan, thiophene, selenophene) and a $\pi$-electron deficient nucleus (pyridine) are fused together. This ultimately raises the question of how the annelation will perturb the electronic structure of each individual nucleus and how this will be manifested for example in the substitution pattern obtained in electrophilic or nucleophilic aromatic substitution on these substrates. Furthermore, these systems are isosteric with quinolines and isoquinolines, which gives them potential pharmacological interest.

A detailed study of some of the thiophene analogues of isoquinoline (thieno[2,3-c]pyridine and thieno[3,2-c]pyridine) has recently been carried out. ${ }^{1-8}$ There are three different isomers (A-C) for each unsubstituted heterocyclic analogue of quinoline (see Scheme 1.)

In the furan series, derivatives of all these forms are known from the literature. However,

* To whom correspondence should be addressed.

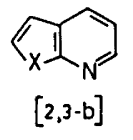

A

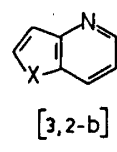

B

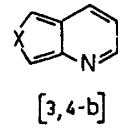

C
Scheme 1.

only one of the parent compounds, namely A (see Scheme 1) is known. In the thiophene series, on the other hand, all three parent compounds and derivatives of them are known (for review $c f$. Ref. 4). In the selenophene series two of the parent compounds (A and B) and some derivatives of them are known. A short summary of the most important methods described in the literature for obtaining the quinoline analogues $\mathrm{B}$, is given below.

The furo[3,2-b]pyridine system has exclusively been prepared from suitably substituted pyridines, and mainly from reaction of 2 -iodo3-hydroxypyridines with various copper acetylides. $^{5-7}$ Recently, another reaction route starting from ortho-substituted pyridines was described..$^{8}$ None of these methods lead to the parent compound.

For the preparation of the thieno[3,2-b]pyridine system there are two important synthetic methods, one of which utilizes 3-vinylpyridines as starting materials and involves treatment with hydrogen sulfide at high temperatures. ${ }^{9,10}$ The parent compound has been prepared in this way, but in low yield $(27 \%) .{ }^{10}$ The other method starts from the hexachlorostannates or 
hydrochlorides of 3-aminothiophenes which are reacted with various 1,3-dicarbonyl compounds. ${ }^{11-17}$ This method has suffered from the unavailability of the 3-amino compounds, but recently an alternative method for their preparation via 3-acetylthiophene has made this route more efficient. ${ }^{17}$

There is only one method described for preparing the selenolo[3,2-b]pyridine system. ${ }^{17}$ This method is completely analogous to the second one described above for the synthesis of the thiophene analogue and it suffers from the same limitation. The modification described above which gave good yields of the thieno[3,2b] parent compound does not seem to give the corresponding selenolo[3,2-b] parent compound under the same conditions. ${ }^{17}$

\section{SYNTHESIS}

This paper describes a new general way to prepare all three $[3,2-b]$ systems utilizing the Friedländer reaction. ${ }^{18}$ The reason that the Friedländer scheme, with one recent exception, ${ }^{10}$ has not been used in the synthesis of furo-, thieno-, and selenolopyridines is probably the lack of suitable starting materials. The preparation of such suitable starting materials, namely 3-amino-2-formylfuran, -thiophene, and -selenophene, were described in the previous paper in this series. ${ }^{20}$

The Friedländer method utilizes the reaction in alkaline or acidic media between an aromatic ortho-aminocarbonyl compound and a carbonyl compound containing an active methylene group $\alpha$ to the carbonyl group (see top of Scheme 2). The amino compounds used in this study are 3-amino-2-formylfuran, 3-amino-2-formylthiophene and 3-amino-2-formylselenophene, which were obtained by reducing the corresponding 3 azido derivatives with hydrogen sulphide in alkaline medium. ${ }^{20}$ However, it proved unnecessary to isolate these ortho-aminoformyl compounds before treating them with the appropriate carbonyl compound. Thus the reaction solutions obtained from the reductions of the azido compounds could be used directly after removal of precipitated sulfur and adjustment of the volumes. The carbonyl compounds used in this study are acetone, pyruvic acid and to a limited extent acetylacetone and acetaldehyde.

Initial trials to react acetaldehyde with 3 . amino-2-formylthiophene in alkaline ethanol were unsuccessful. No thieno[3,2-b]pyridine could be isolated under these conditions (see Scheme 2). Since it is known ${ }^{18}$ that aldehydes in certain cases can give little or no product, other synthetic paths leading to the parent compounds were sought. Quinoline-2-carboxylic acid is known to decarboxylate easily on heating and give high yields of quinoline. ${ }^{21}$ In order to obtain the corresponding carboxylic acids in these series, the ortho-amino aldehydes were treated with freshly distilled pyruvic acid in alkaline ethanol/water (see Scheme 2). This gave 5-carboxyfuro[3,2]pyridine (I), 5-carboxythieno[3,2-b]pyridine (II) and 5-carboxyselenolo[3,2-b]pyridine (III) in moderate yields (43$48 \%$ ). The yield did not improve even if a large excess of pyruvic acid was used. These 5carboxy compounds could be smoothly decarboxylated simply by heating above their melting points (see Scheme 2). Thus the parent compounds, furo[3,2-b]pyridine (IV), thieno[3,2b]pyridine (V), and selenolo[3,2-b]pyridine (VI) were obtained in good to excellent yields (78-99\%).

When the ortho-amino aldehydes were treated with excess of acetone in alkaline ethanol/water, 5-methylfuro[3,2-b]pyridine (VII), 5-methylthieno[3,2-b]pyridine (VIII), and 5-methylselenolo[3,2-b]pyridine (IX) were formed in good yields $(71-87 \%$ ) (see Scheme 2.)

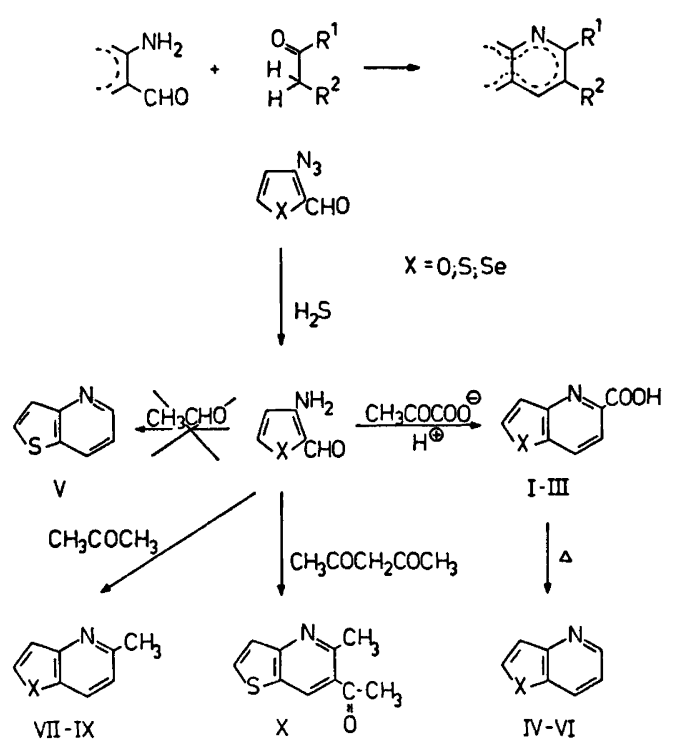

Scheme 2.

Acta Chem. Scand. B 29 (1975) No. 2 
3-Amino-2-formylthiophene was also treated with acetylacetone in alkaline ethanol. This gave 6-acetyl-5-methylthieno[3,2-b]pyridine (X) in good yield (67\%) (see Scheme 2.)

The results of the reactions presented above

Table 1. ${ }^{1 \mathrm{H}} \mathrm{NMR}$ chemical shifts $(\delta)$ and coupling constants $(\mathrm{Hz})$ in 5-carboxy substituted furo-, thieno-, and selenolo[3,2-b]pyridines in hexadeuterio dimethyl sulfoxide solution at 60 MHz.

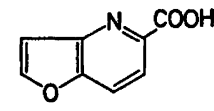

I<smiles>O=C(O)c1ccc2sccc2n1</smiles>

II

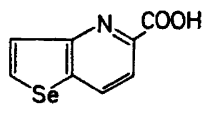

III

\begin{tabular}{llll}
\hline & I & II & III \\
\hline$\delta(H-2)$ & 8.51 & 8.33 & 8.78 \\
$\delta(H-3)$ & 7.33 & 7.76 & 7.96 \\
$\delta(H-6)$ & 8.21 & 8.11 & 8.02 \\
$\delta(H-7)$ & 8.21 & 8.70 & 8.80 \\
$J_{2,3}$ & 2.30 & 5.50 & 5.95 \\
$J_{s, 7}$ & 0.6 & 0.6 & 0.6 \\
$J_{67}$ & - & 8.35 & 8.20 \\
\hline
\end{tabular}

Table 2. ${ }^{1} \mathrm{H}$ NMR chemical shifts $(\delta)$ and coupling constants $(\mathrm{Hz})$ in furo-, thieno-, and selenolo[3,2-b]pyridines in carbon tetrachloride solution at $60 \mathrm{MHz}$.

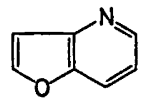

IV

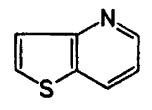

$\mathrm{y}$

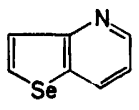

vi

\begin{tabular}{lccc}
\hline & IV & V & VI \\
\hline$\delta(\mathrm{H}-2)$ & 7.99 & 7.60 & 8.14 \\
$\delta(\mathrm{H}-3)$ & 6.95 & 7.49 & 7.74 \\
$\delta(\mathrm{H}-5)$ & 8.46 & 8.59 & 8.57 \\
$\delta(\mathrm{H}-6)$ & 7.17 & 7.04 & 7.04 \\
$\delta(\mathrm{H}-7)$ & 6.64 & 8.00 & 8.09 \\
$J_{2,3}$ & 2.20 & 5.60 & 5.95 \\
$J_{5,6}$ & 4.70 & 4.65 & 4.60 \\
$J_{5,7}$ & 1.30 & 1.60 & 1.50 \\
$J_{6,7}$ & 8.25 & 8.75 & 8.10 \\
$J_{2,6}$ & $\leq 0.2$ & 0.40 & 0.30 \\
$J_{3,7}$ & 1.00 & 0.75 & 0.70 \\
\hline
\end{tabular}

Acta Chem. Scand. B 29 (1975) No. 2
Table 3. ${ }^{1} \mathrm{H}$ NMR chemical shifts $(\delta)$ and coupling constnats $(\mathrm{Hz})$ in 5-methyl substituted furo-, thieno-, and selenolo[3,2-b]pyridines in carbon tetrachloride solution at $60 \mathrm{MHz}$.<smiles>Cc1ccc2occc2n1</smiles>

VII<smiles>Cc1ccc2sccc2n1</smiles>

VIII<smiles>Cc1ccc2[se]ccc2n1</smiles>

IX

\begin{tabular}{lllr}
\hline & VII & VIII & IX \\
\hline$\delta(\mathrm{H}-2)$ & 7.73 & 7.57 & 8.09 \\
$\delta(\mathrm{H}-3)$ & 6.84 & 7.41 & 7.67 \\
$\delta(\mathrm{H}-6)$ & 6.91 & 6.92 & 6.88 \\
$\delta(\mathrm{H}-7)$ & 7.50 & 7.87 & 7.93 \\
$\delta\left(\mathrm{CH}_{8}\right)$ & 2.57 & 2.58 & 2.58 \\
$\alpha_{2,3}$ & 2.25 & 5.60 & 5.90 \\
$J_{6,7}$ & 8.45 & 8.40 & 8.20 \\
$J_{3,7}$ & 0.95 & 0.70 & 0.70 \\
2,8 & 0.40 & 0.35 & $\leq 0.2$ \\
\hline
\end{tabular}

and the availability of a great number of other carbonyl compounds capable of reacting in a similar manner show clearly that the Friedländer scheme is a powerful complement to existing methods for annelating pyridine rings to the furan, thiophene or selenophene nucleus.

\section{${ }^{1} \mathrm{H}$ NMR SPECTRA}

The NMR data for compounds I to IX are given in Tables 1, 2, and 3. The NMR data for compound $\mathrm{X}$ are given in the experimental part. The assignment of different bands to different protons in the new compounds has been based on knowledge of shifts and coupling constants in furans, thiophenes, selenophenes, and quinolines, and on comparison with literature data for previously prepared compounds in these series. Thus, the NMR spectra of thieno[3,2-b]pyridine (V), selenolo[3,2-b]pyridine (VI), and their 5-methyl derivatives (VIII, IX) have been reported earlier. ${ }^{18,17}$

The analyses of the spectra were made on the assumption that it was possible to treat the molecules as consisting of two isolated systems of protons, one consisting of the protons in the five-membered ring and the other of the protons in the pyridine nucleus. This assumption is not strictly valid since there are long-range couplings between the rings. However, since fow 


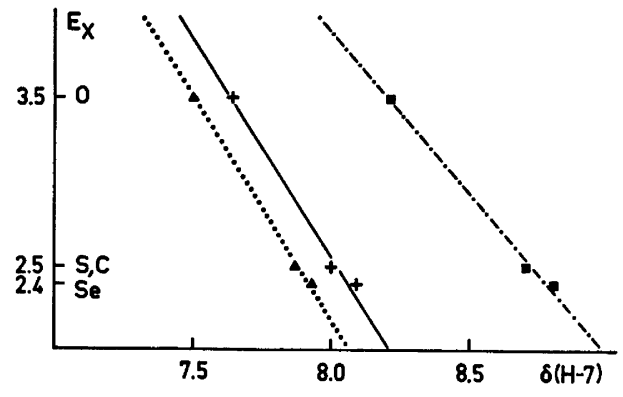

Fig. 1. Correlations between the electronegativity of the heteroatom and the 7-proton chemical shifts for furo-, thieno- and selenolo[3,2b]pyridine $(+\stackrel{-}{\longrightarrow}=0.99)$ and their 5 . methyl $(\Delta \cdots, r \approx 1.0)$ and 5 -carboxy ( $-\cdot-, r \approx 1.0$ ) derivatives. The corresponding values for quinoline and 2-methylquinoline are included.

of the $A B$ systems involved showed signs of strong coupling, it seemed reasonable that this assumption should lead only to minor errors. In order to determine if this was the case, the NMR spectra of the three parent compounds (IV, V, VI) were also analyzed as 5 -spin systems in an iterative mode utilizing an extended version of the QCPE program UEAITR (No. 188). ${ }^{22}$ The numerical differences for the two types of analyses were in the same range as the experimental error. The NMR data given in Table 2 are those obtained from the iterative analyses.

It should be pointed out that the 7-proton absorptions for the fused pyridine derivatives are systematically shifted to lower field on going from the furan-fused to the selenophenefused systems. This order $O>S>S e$ is the same as that of the electron-donating mesomeric effect of the heteroatom. Excellent linear correlations with the electronegativity of the heteroatoms $(\mathrm{O}=3.5, \mathrm{~S}=2.5$, and $\mathrm{Se}=2.4)$ were obtained both for the parent compounds and for the 5-methyl and 5-carboxy derivatives (Fig. 1). For comparison the shifts for quinoline ${ }^{23}$ and 2-methylquinoline ${ }^{24}$ were also included $(C=2.5)$, and were found to fit the correlation well. The effects of the heteroatom on the 5- and 6-proton shifts are very small and for the 6-proton shifts perhaps even of the opposite direction.

It appears that electron donation from the five-membered ring to the six-membered ring, as expressed in resonance form $\mathrm{D}$, is important, although it is evident from resonance forms $\mathbf{E}$

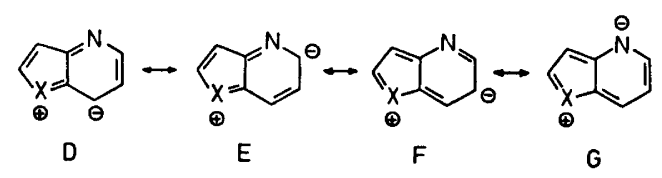

to $\mathrm{G}$ that the electron-donation from the fivemembered ring can reach all positions in the pyridine ring, especially the nitrogen.

Similar observations were made a few years ago ${ }^{25}$ in a study of the ${ }^{1} \mathrm{H}$ NMR parameters of 2-methylbenzoxazole, -benzothiazole, and -benzoselenazole. Linear correlations between the electronegativity of the heteroatoms and several ${ }^{1} \mathrm{H}$ and ${ }^{13} \mathrm{C}$ NMR parameters have also been observed in monocyclic furans, thiophenes, selenophenes, and tellurophenes. ${ }^{26}$

It should be pointed out that in the discussion above no consideration of the effect of the magnetic anisotropy of the heteroatom has been taken into account.

The long-range couplings found in this work are consistent with the so-called "zig-zag" path hypothesis, and similar cases have been pre. viously noted in these types of systems.,17,27

\section{EXPERIMENTAL}

Furo[3,2-b]pyridine-5-carboxylic acid (I). 5.7 $\mathrm{g}(0.042 \mathrm{~mol})$ of 3 -azido-2-formylfuran ${ }^{20}$ was dissolved in $50 \mathrm{ml}$ of ethanol containing three drops of piperidine. The solution was cooled to $10^{\circ} \mathrm{C}$ and hydrogen sulfide was bubbled through the solution with continued cooling. An exothermic reaction with evolution of nitrogen gas took place. The rate of addition of hydrogen sulfide was such that the temperature was kept below $25^{\circ} \mathrm{C}$. After about $45 \mathrm{~min}$, the evolution of nitrogen had ceased and the reaction mixture was cooled to $0{ }^{\circ} \mathrm{C}$, whereupon precipitated sulfur was filtered off. The filtrate was concentrated to about $10 \mathrm{ml}$, by evaporation, and treated with $33 \mathrm{ml}$ of $15 \%$ sodium hydroxide solution containing $7.4 \mathrm{~g}(0.084 \mathrm{~mol})$ of freshly distilled pyruvic acid. The reaction mixture was carefully heated to $60^{\circ} \mathrm{C}$ and stirred at this temperature for $3 \mathrm{~h}$, after which it was allowed to attain room temperature and placed in a refrigerator over night. The resulting sodium salt of the acid was filtered off and dissolved in the smallest possible amount of hot water, followed by acidification with dilute hydrochloric acid $(\mathrm{pH}=4)$. After slow cooling to $5{ }^{\circ} \mathrm{C}$ the precipitated acid was filtered off. The crude product was dried in a desiccator over 
conc. sulfuric acid for $24 \mathrm{~h}$, giving $3.0 \mathrm{~g}$ (43\%) of the acid. An analytical sample obtained by recrystallization from toluene showed an IR spectrum identical with that of the crude product, m.p. $174.0-176.0{ }^{\circ} \mathrm{C}$. IR spectrum (KBr): $\mathrm{CO}=1700 \mathrm{~cm}^{-1}$. NMR spectrum (DMSO$d_{6}$ ): see Table 1. (Found: $\mathrm{C}$ 58.7; $\mathrm{H}$ 3.19; O 29.2 ; m.wt. 163. Calc. for $\mathrm{C}_{8} \mathrm{H}_{5} \mathrm{NO}_{3}: \mathrm{C} 58.9 ; \mathrm{H}$ 3.10; O 29.4; m.wt. 163.14).

Thieno[3,2-b]pyridine-5-carboxylic acid (II) was prepared as described for I from $3.0 \mathrm{~g}$ $(0.020 \mathrm{~mol})$ of 3-azido-2-formylthiophene, ${ }^{20}$ $20 \mathrm{ml}$ of ethanol, two drops of piperidine, hydrogen sulfide, $3.5 \mathrm{~g}(0.040 \mathrm{~mol})$ of pyruvic acid, and $18 \mathrm{ml}$ of $15 \%$ sodium hydroxide solution, yielding $1.7 \mathrm{~g}(48 \%)$ of the product. An analytical sample obtained by recrystallization from toluene showed an IR spectrum identical with that of the crude product; m.p. 201.5 $202.0^{\circ} \mathrm{C}$. IR spectrum (KBr): $\mathrm{CO}=1700 \mathrm{~cm}^{-1}$. NMR spectrum (DMSO- $d_{6}$ ): see Table 1. (Found: C 53.6; H 2.89; S 17.9; m.wt. 179. Calc. for $\mathrm{C}_{8} \mathrm{H}_{5} \mathrm{NO}_{2} \mathrm{~S}: \quad \mathrm{C} \quad 53.6 ; \mathrm{H} \quad 2.82 ; \mathrm{S} \quad 17.9 ;$ m.wt. 179.20).

Selenolo[3,2-b]pyridine-5-carboxylic acid (III) was prepared as described above for I from 5.4 g $(0.027 \mathrm{~mol})$ of 3-azido-2-formylselenophene, ${ }^{20}$ $40 \mathrm{ml}$ of ethanol, two drops of piperidine, hydrogen sulfide, $4.8 \mathrm{~g}(0.055 \mathrm{~mol})$ of pyruvic acid, and $60 \mathrm{ml}$ of $15 \%$ sodium hydroxide solution, yielding after recrystallization from toluene $2.6 \mathrm{~g}(42 \%)$ of the product; m.p. $167.0-169.0{ }^{\circ} \mathrm{C}$. IR spectrum $(\mathrm{KBr}): \mathrm{CO}=1670$ $\mathrm{cm}^{-1}$. NMR spectrum (DMSO-d $d_{6}$ ): see Table 1. (Found: C 42.7; H 2.37; Se 34.9; m.wt. 227. Calc. for $\mathrm{C}_{8} \mathrm{H}_{5} \mathrm{NO}_{2} \mathrm{Se}$ : C 42.5; $\mathrm{H}$ 2.23; Se 34.9; m.wt. 226.10).

Furo[3,2-b]pyridine (IV). $1.6 \mathrm{~g}(0.0098 \mathrm{~mol})$ of furo[3,2-b]pyridine-5-carboxylic acid (I) was transferred to a Claisen flask, which was then heated with a gas burner. The substance melted with sublimation. The heating was continued until evolution of carbon dioxide had ceased. The resulting liquid was allowed to cool, whereupon it was distilled at reduced pressure. $0.9 \mathrm{~g}(78 \%)$ of a light yellow oil with a smell of quinoline was obtained; b.p. $79-80{ }^{\circ} \mathrm{C} / 12$ $\mathrm{mmHg}, n_{\mathrm{D}}{ }^{10}=1.5753$. NMR spectrum $\left(\mathrm{CCl}_{4}\right)$ : see Table 2. (Found: C 70.4; H 4.41; O 13.6; m.wt. 119. Calc. for $\mathrm{C}_{7} \mathrm{H}_{6} \mathrm{NO}: \mathrm{C} 70.6 ; \mathrm{H} \mathrm{4.24}$; O 13.4; m.wt. 119.13).

Thieno[3,2-b]pyridine (V) was prepared as described above for IV from $2.7 \mathrm{~g}(0.015 \mathrm{~mol})$ of thieno[3,2-b]pyridine-5-carboxylic acid (II), yielding $2.0 \mathrm{~g}(99 \%)$ of the crude product, which by GLC (BDS $10 \%$ Chrom. W. $2 \mathrm{~m}$ ) showed only one component. Its IR spectrum was identical with that of the distilled product (1.1 g); b.p. $107-108{ }^{\circ} \mathrm{C} / 10 \mathrm{mmHg}, n_{\mathrm{D}}{ }^{21}=$ 1.6391. (Lit. value ${ }^{16}$ b.p. $82-84^{\circ} \mathrm{C} / 2 \mathrm{mmHg}$ ). NMR spectrum $\left(\mathrm{CCl}_{4}\right)$ : see Table 2.

Selenolo[3,2-b] pyridine (VI) was prepared as described above for IV from $2.8 \mathrm{~g}(0.012 \mathrm{~mol})$ of selenolo[3,2-b]pyridine-5-carboxylic acid (III), yielding $2.2 \mathrm{~g}(98 \%)$ of the crude product, showing a gas chromatogram (BDS $10 \%$ Chrom. W. $2 \mathrm{~m}$ ) with only one peak and an IR spectrum identical with that of the distilled fraction (1.6 g), b.p. $127-129{ }^{\circ} \mathrm{C} / 10 \mathrm{mmHg}$, m.p. 35.5-37.0 ${ }^{\circ} \mathrm{C}$. (Lit. value ${ }^{17}$ m.p. $30^{\circ} \mathrm{C}$ ). NMR spectrum $\left(\mathrm{CCl}_{4}\right)$ : see Table 2.

5-Methylfuro[3,2-b]pyridine (VII). $\quad 7.0 \quad \mathrm{~g}$ $(0.051 \mathrm{~mol})$ of 3-azido-2-formylfuran ${ }^{20}$ was dissolved in $75 \mathrm{ml}$ of ethanol containing three drops of piperidine. The solution was cooled to $10^{\circ} \mathrm{C}$ whereupon hydrogen sulfide was bubbled through it with continued cooling. An exothermic reaction with evolution of nitrogen gas took place. The rate of the addition of hydrogen sulfide was such that the temperature was kept below $20^{\circ} \mathrm{C}$. After about $45 \mathrm{~min}$ the evolution of nitrogen had ceased, the reaction mixture was cooled to $0{ }^{\circ} \mathrm{C}$, and precipitated sulfur was filtered off. The filtrate was treated with a mixture of $25 \mathrm{ml}$ of acetone and $25 \mathrm{ml}$ of water, followed by the addition of $10 \mathrm{ml}$ of $15 \%$ sodium hydroxide solution. The reaction mixture, which turned dark, was stirred at $55^{\circ} \mathrm{C}$ for $16 \mathrm{~h}$, whereupon it was diluted with $150 \mathrm{ml}$ of water and extracted four times with ether. The combined ether phases were extracted four times with $1 \mathrm{~N}$ hydrochloric acid, and the acidic phases were made alkaline with pellets of sodium hydroxide, and then extracted with ether. The combined ether phases were dried over magnesium sulfate and concentrated, giving 4.8 $\mathrm{g}(71 \%)$ of a red-brown oil showing only one peak in GLC (OV 17, 3 \% Chrom. Q, $3 \mathrm{~m}$ ) and an IR spectrum identical with that of the distilled fraction, b.p. $81.5-82.0{ }^{\circ} \mathrm{C} / 8 \mathrm{mmHg}, n_{\mathrm{D}^{21}}$ $=1.5593$. NMR spectrum $\left(\mathrm{CCl}_{4}\right)$ : see Table 3 . (Found: C 70.3; H 5.32; O 12.1; m.wt. 133. Calc. for $\mathrm{C}_{8} \mathrm{H}_{7} \mathrm{NO}$ : $\mathrm{C} 72.2 ; \mathrm{H}$ 5.31; $\mathrm{O} 12.0$; m.wt. 133.16).

5-Methylthieno[3,2-b]pyridine (VIII) was prepared as described above for VII from $4.9 \mathrm{~g}$ $(0.032 \mathrm{~mol})$ of 3 -azido-2-formylthiophene, ${ }^{20} 40$ $\mathrm{ml}$ of ethanol, two drops of piperidine, hydrogen sulfide, $20 \mathrm{ml}$ of acetone in $20 \mathrm{ml}$ of water, and $10 \mathrm{ml}$ of $15 \%$ sodium hydroxide solution. Upon evaporation, $3.9 \mathrm{~g}(81 \%)$ of a red-brown oil was obtained, showing only one peak in GLC (OV 17, $3 \%$ Chrom. Q, $3 \mathrm{~m}$ ) and an IR spectrum identical with that of the distilled fraction, b.p. 114.5-116.5 ${ }^{\circ} \mathrm{C} / 8 \mathrm{mmHg}, n_{\mathrm{D}}{ }^{21}=1.6284$. (Lit. value: ${ }^{16}$ b.p. $\left.95-98^{\circ} \mathrm{C} / 5 \mathrm{mmHg}\right)$. NMR spectrum $\left(\mathrm{CCl}_{4}\right)$ : see Table 3 .

5-Methylselenolo[3,2-b]pyridine (IX) was prepared as described above for VII from $6.0 \mathrm{~g}$ $(0.030 \mathrm{~mol})$ of 3-azido-2-formylselenophene, ${ }^{20}$ $40 \mathrm{ml}$ of ethanol, two drops of piperidine, hydrogen sulfide, $25 \mathrm{ml}$ of acetone in $25 \mathrm{ml}$ of water, and $10 \mathrm{ml}$ of $15 \%$ sodium hydroxide solution. Upon evaporation, $5.2 \mathrm{~g}(87 \%)$ of a red-brown oil was obtained, showing only one peak in GLC (OV 17, $3 \%$ Chrom. Q, $3 \mathrm{~m}$ ) and an IR spectrum identical with that of the distilled fraction, b.p. $135-140^{\circ} \mathrm{C} / 15 \mathrm{mmHg}$, m.p. $46.0-48.0^{\circ} \mathrm{C}$. (Lit. value: ${ }^{17}$ m.p. $47-48{ }^{\circ} \mathrm{C}$ ). NMR spectrum $\left(\mathrm{CCl}_{4}\right)$ : see Table 3 . 
5-Methyl-6-acetyl[3,2-b]pyridine $(X)$ was prepared as described above for $I$ and VII from $3.2 \mathrm{~g}(0.021 \mathrm{~mol})$ of 3-azido-2-formylthiophene, ${ }^{20}$ $40 \mathrm{ml}$ of ethanol, two drops of piperidine, and hydrogen sulfide. After filtration of precipitated sulfur, $2.7 \mathrm{~g}(0.027 \mathrm{~mol})$ of acetoacetone and another seven drops of piperidine were added. The reaction mixture was refluxed for $18 \mathrm{~h}$, whereupon the volume of the solution was concentrated to a third and poured into $100 \mathrm{ml}$ of ice and water with vigorous stirring. The precipitate was filtered off, giving $2.7 \mathrm{~g} \mathrm{(67 \% )}$ of the product. An analytical sample obtained by recrystallization from toluene showed an IR spectrum identical with that of the crude product; m.p. $131.5-132.5{ }^{\circ} \mathrm{C}$. IR spectrum (KBr): $\mathrm{CO}=1675 \mathrm{~cm}^{-1}$. NMR spectrum $\left(\mathrm{CDCl}_{3}\right)$ : $\delta 7.50$ (H-3), 7.91 (H-2), 8.50 (H-7), 2.65 and $2.90\left(\mathrm{CH}_{3}\right.$ or $\left.\mathrm{COCH}_{3}\right) ; J_{8,3} 5.30 \mathrm{~Hz}, J_{3,7} 0.7 \mathrm{~Hz}$. (Found: C 62.6; H 4.70; ' 16.9 ; m.wt. 191. Calc. for $\mathrm{C}_{10} \mathrm{H}_{9} \mathrm{NOS}$ : $\mathrm{C}$ 62.8; H 4.75; $\mathrm{S}$ 16.8; m.wt. 191.26).

The ${ }^{1} \mathrm{H}$ NMR spectra were obtained with a Varian A.60 high resolution spectrometer. The IR spectra were recorded on a Perkin.Elmer model 257. The gas chromatograph used was a Perkin-Elmer 900 analytical instrument. Mass spectra were obtained with an LKB 9000 mass spectrometer. Elementary analyses were carried out at the Analytical Department of the Chemical Institute and by Dornis und Kolbe, Mikroanalytisches Laboratorium, Mühlheim/Ruhr.

Acknowledgement. Grants from the Swedish Natural Science Research Council (to S.G. and A.-B.H.) and from the Royal Physiographic Society (to C.W.) are gratefully acknowledged.

\section{REFERENCES}

1. Gronowitz, S. and Sandberg, E. Ark. Kemi 32 (1970) 217.

2. Gronowitz, S. and Sandberg, E. Ark. Kemi 32 (1970) 249.

3. Gronowitz, S. and Sandberg, E. Ark. Kemi 32 (1970) 269.

4. Schneller, S. W. Int. J. Sulfur Chem. B 7 (1972) 309.

5. Mladenović, S. A. and Castro, C. E. J. Heterocycl. Chem. 5 (1968) 227.

6. Abramenko, P.I. and Zhiryakov, V.G. Zh. Vses. Khim. Obshchest. 17 (1972) 695; Chem. Abstr. 78 (1973) 71953j.

7. Owsley, D. C. and Castro, C. E. Org. Syn. 52 (1972) 128.

8. Hymans, W. E. and Cruickshawk, P.A. $J$. Heterocycl. Chem. 11 (1974) 231.

9. Klemm, L. H. and Reed. D. J. Org. Chem. 25 (1960) 1816.

10. Klemm, L. H., Shabtai, J., McCoy, D. R. and Kiang, W. K. T. J. Heterocycl. Chem. 5 (1968) 883.
11. Abramenko, P.I. and Zhiryakov, V. G. U.S.S.R. 165,729; Chem. Abstr. 62 (1965) 6488g.

12. Zhiryakov, V.G. and Abramenko, P.I. Khim. Geterosikl. Soedin. 1 (1965) 334.

13. Abramenko, P. I. Khim. Geterosikl. Soedin. 3 (1967) 368.

14. Abramenko, P.I. Khim. Geterosikl. Soedin. 7 (1972) 468.

15. Abramenko, P. I. Zh. Vses. Khim. Obshchest. 17 (1972) 478; Chem. Abstr. 77 (1972) $15020 \mathrm{j}$.

16. Klemm, L. H., Klopfenstein, C. E., Zell, R., McCoy, D. R. and Klemm, R.A. $J$. Org. Chem. 45 (1969) 347.

17. Outurquin, F., Au-kow, G. and Paulmier, C. C. R. Acad. Sci 277 (1973) 29.

18. Elderfield, R. C. Heterocyclic Compounds, Wiley, New York 1952, Vol. 4, p. 45.

19. Schäfer, v., H., Gewald, $K$. and Hartman, H. J. Prakt. Chem. 316 (1974) 169.

20. Gronowitz, S., Westerlund, C. and Hörnfeldt, A.-B. Acta Chem. Scand. B 29 (1975) 224.

21. Paquette, L. A. Principles of Modern Heterocyclic Chemistry, Benjamin, Reading, Mass. 1968, p. 296.

22. Johannesen, R. B., Ferretti, J. A. and Harris, R. K. J. Magn. Resonance 3 (1970) 84.

23. Black, P. J. and Hefferman, M. L. Aust. J. Chem. 17 (1964) 558.

24. Mondelli, R. and Merlini, L. Tetrahedron 22 (1966) 3253 .

25. Tobiason, F. L. and Goldstein, J.H. Spectrochim. Acta $A 23$ (1967) 1385.

26. Fringuelli, F., Gronowitz, S., Hörnfeldt, A.-B., Johnson, I. and Taticchi, A. Acta Chem. Scand. B 28 (1974) 175.

27. Eloy, F. and Deryckere, A. J. Heterocycl. Chem. 8 (1971) 57.

\section{Received August 23, 1974.}

